\title{
RevistAleph
}

\section{MEU MESTRE E EU}

Marcelo Mocarzel ${ }^{86}$

Em uma tarde de março, meu telefone tocou. Era Jorge Najjar. Na época eu era um recém graduado em Pedagogia, aspirante ao mestrado em Educação e ele era vicediretor da Faculdade de Educação da UFF, onde eu havia participado do último processo seletivo do mestrado e meu projeto fora reprovado. Ouvi dizer, pelos corredores, que para ter mais chances, eu deveria ingressar em um grupo de pesquisas, para me familiarizar com o linguajar, com as exigências da academia. Por intermédio da professora Marcia Pessanha, consegui ser indicado ao professor Jorge, que estava criando seu grupo de pesquisas. Ele me perguntou, com sua voz ao mesmo tempo firme e doce, o que eu queria pesquisar. Na minha ingenuidade, eu respondi: "Educação". Ele retrucou rindo: "Sim, disso eu sei, mas o que em educação?". Eu respondi o que me veio à cabeça: “Gestão!”. Essa ligação, de pouco mais de 2 minutos, mudou completamente a minha vida e, acredito eu, a de muitas outras pessoas.

Na quarta-feira seguinte, dia 24 de março, às 2 horas da tarde, me apresentei como bom calouro na sala da vice-direção da Faculdade de Educação, no campus do Gragoatá, em Niterói. Eu me lembro de olhar para aquela paisagem bucólica à beira da Baía e sentir, que de alguma forma, aquele ali seria meu lugar. Sua sala era pequena e contava com três mesas, duas retangulares, formando um $L$ e uma mesinha redonda com quatro cadeiras. Jorge estava de lado, de camisa amarela, digitando no teclado, com o óculos na ponta do nariz. Ele olhou para mim e abriu um largo sorriso: "Senta aí filho, vamos esperar os outros chegarem." Como em uma primeira entrevista de emprego, fiquei sem saber o que fazer, para onde olhar e o silêncio era interrompido apenas pelas suas fortes batidas nas teclas do computador. Olhei aquelas pilhas de

\footnotetext{
${ }^{86}$ Doutor em Comunicação Social (PUC-Rio) e Mestre em Educação pela UFF, onde realizou estágio pósdoutoral na Faculdade de Educação entre 2018 e 2019. Professor do quadro permanente do PPG Educação da Universidade Católica de Petrópolis e professor nos cursos de graduação e pós-graduação do Unilasalle-RJ. Graduado em Pedagogia (Unilasalle-RJ) e em Comunicação Social / Publicidade e Propaganda (PUC-Rio).
} 


\section{RevistAleph}

folhas, xerox, livros, aquela "desorganização arqueológica", como ele chamava, com camadas e mais camadas de trabalho e pensei: "Como alguém se encontra desse jeito?".

Logo depois, para meu alívio, três estudantes de mestrado ingressaram na salinha e se apresentaram: Lucy, Adriana e Rogério. Já os conhecia por e-mail, mas ali pela primeira vez os vi pessoalmente. Os três eram recém-ingressados no mestrado e seriam orientados pelo Najjar. Aquela reunião, em março de 2010, foi a pedra fundamental da criação do Nugeppe - Núcleo de Estudos em Gestão e Políticas Públicas em Educação, um grupo de pesquisa, mas antes de tudo, um grupo de afetos. Naquela primeira reunião, ele havia pedido que eu trouxesse um anteprojeto, com aquilo que desejava pesquisar. Eu juro que me esforcei. Passei dias construindo algo que eu acreditava ser realmente bom, repleto de citações de autores consagrados, seguindo todas as normas que o edital do mestrado propunha, algo que fosse, como Jorge depois me ensinou, "um cartão de visitas" para mim naquele espaço almejado. Ele puxou uma cadeira e se sentou conosco, pedindo que nos apresentássemos. Por fim, pediu que eu distribuísse as cópias do meu anteprojeto, que seria lido pelos quatro e em seguida, comentado. Antes, ele fez uma fala - que ao longo dos anos se tornou um clássico - que a crítica intelectual era um sinal de respeito do colega, que não era pessoal e que "a massa só cresce quando a gente bate". Levei aquilo na maior tranquilidade e fizemos silêncio para que lessem minhas 8 páginas de pretensa genialidade concentrada.

Após a leitura, para mim, todo aquele clima de acolhida desapareceu. O céu ficou nublado. Eles quatro, mas principalmente Jorge Najjar, foram impiedosos com meu texto: falaram que aquilo não era um projeto, que não tinha objetivo, que a justificativa não justificava e todo tipo de ofensa impessoal que só o autor do texto é capaz de enxergar. Fui atropelado por um rolo compressor, mantive meu sorriso amarelo, agradeci e emudeci. Fiquei contando os minutos para ser libertado daquela câmara de tortura. Eu me lembro perfeitamente do meu trajeto em direção ao carro, pensando: "Eu nunca mais vou pisar aqui!". Saí envergonhado, triste, decepcionado comigo mesmo, achando que a vida acadêmica não era para mim. Os dias foram passando e tive coragem de reler o meu projeto e constatar que eu só havia ouvido 


\section{RevistAleph}

verdades. Que aquele projeto era verde como eu e que nós precisávamos amadurecer. Foi assim que resolvi voltar na quarta-feira seguinte.

Depois desse momento-chave, tudo começou a fazer sentido. Jorge me incentivava com seu jeito carinhoso, atencioso, com seu bom humor e mesmo quando escrevia "Feio!" ao corrigir meus parágrafos. Nós rapidamente criamos identificações várias: ambos descendentes de libaneses, gostávamos tanto de ler e estudar, como de comer uma paçoquinha com café e falar da vida. Fomos, pouco a pouco criando uma cumplicidade que se refletiu na minha aprovação no mestrado em 2011, quando ele me ligou depois que o resultado foi homologado e disse: "Parabéns, mestrando!". Daí em diante, comecei a construir com ele uma relação simbiótica: escrevíamos juntos para congressos, eu o ajudava a organizar seu sítio arqueológico e sua agenda, ele me ajudava revisando meus trabalhos das disciplinas e tirando minhas dúvidas sobre os autores. Construí minha maneira de dar aulas vendo ele dar aulas, aprendi a analisar criticamente um texto vendo ele nas bancas e no grupo de pesquisa, aprendi muito sobre gestão de pessoas observando sua serenidade como vice-diretor, diante dos maiores absurdos que lhe eram relatados. Nunca foi grosseiro com ninguém, nunca deixou a razão de lado, mesmo colocando emoção em tudo que fazia. E foi ele que me deu todas as oportunidades iniciais, quando eu era apenas um aspirante, sofrendo certa desconfiança por ser oriundo da escola privada.

Quando eu e meus contemporâneos Sheila, Edylane e Simone estávamos escrevendo nossas metodologias para as dissertações, ele se divertia ao dizer, com a boca cheia, após ler os manuscritos: "Isto não é uma metodologia". Até que eu resolvi armar uma arapuca para ele. Peguei sua tese de doutorado, fui na metodologia e criei um quadro esquemático, indicando todos os pontos que ele abordava, ou seja, o trajeto do texto. Espelhei aquele roteiro para o meu objeto e construí meu texto metodológico com base naquele que tinha sido o seu. Entreguei o texto e aguardei ele dizer que aquilo não era uma metodologia, pronto para dar o bote (nem sei se de fato eu teria coragem de confrontá-lo, é verdade)... Quando acabou, ele girou o pescoço, passou o polegar e o indicador na sua barba e disse: "Tem alguns problemas, algumas partes sem sentido, mas mesmo com tudo isso, posso dizer que isto é uma metodologia!". Foi alegria geral, 


\section{RevistAleph}

comemoração de gol, enquanto ele ria da nossa cara e se orgulhava daquele momento heurístico. Tempos depois contei para ele essa história e ele gargalhava, e passei anos contando para os novos orientandos dele quando me pedia.

Com Jorge descobri como o funcionário público, com dedicação exclusiva, pode trabalhar muito mais do que as horas previstas. Sua generosidade sempre o sobrecarregou de textos para ler, de orientandos herdados, de projetos para integrar, de artigos para dar parecer... Nunca soube dizer não! Ao longo dos anos fomos desenvolvendo uma cumplicidade sem tamanho, que me permitia substituí-lo em aulas, ajudar na correção dos trabalhos e até na resposta dos e-mails. Ele dizia que estava se tornando uma pessoa jurídica, nós tínhamos suas senhas de tudo. Isso se deve muito à entrada de Karine ao grupo, que ocupou um lugar muito especial ao lado dele, ajudando-o em todas as esferas de sua vida. Eu me emociono só de me lembrar do esforço que ela empreendeu para que a banca de titular de Jorge pudesse acontecer em meio à pandemia e à sua doença. Sem dúvidas, a ascensão profissional que Jorge teve nos últimos dez anos, e nós dois consequentemente, se deve muito a este triunvirato que constituímos. Ele brincava que suas próximas tatuagens seriam Marcelo, no braço direito, e Karine no braço esquerdo, ou vice-versa. Não tivemos tempo para isso, infelizmente.

Após deixar a direção da Faculdade de Educação, Jorge conseguiu focar em suas pesquisas e no NUGEPPE. Publicou diversos artigos e organizou mais de uma dezena de obras e dossiês, tendo publicado inclusive sua tese na íntegra, em um livro editado pela EdUFF. Tornou-se diretor estadual da ANPAE, depois vice-presidente Sudeste; coordenador regional da ANFOPE e na sequência seu $1^{\circ}$ tesoureiro; elegeu-se coordenador do Programa de Pós-graduação em Educação da UFF e conseguiu, com um trabalho belíssimo, trazer a Reunião da ANPEd para Niterói, sendo Coordenador-geral da Comissão Local até as vésperas do evento, pouco antes de descobrir sua doença. Para além disso, firmou um profícuo convênio com a Colômbia, em que pesquisadores brasileiros e colombianos realizaram diversos intercâmbios. Foi designado Conselheiro Estadual de Educação, após anos atuando com brilhantismo no Conselho Municipal de 


\section{RevistAleph}

Niterói. Enfim, conquistas dignas de um professor titular de uma das maiores universidades do país.

Jorge nos ensinava com amor, mas sempre com verdade. Nunca se privou de nos corrigir, mesmo que em público, sem o menor receio de constrangimentos. Sabia elevar nossa autoestima e, ao mesmo tempo, nos dar consciência da realidade e de nossas limitações. Como gostava de dizer, aprendeu com Gramsci a ser um pessimista na teoria e um otimista na prática. De longe, foi o melhor marido e pai que já vi, e olha que conheci milhares em tantos anos de gestão escolar; Rosana, Alex e Rafa podem atestar isso. Pena que não conseguiu ser avô, pois seria imbatível nessa função! Era uma fonte inesgotável de conhecimento, de tiradas geniais, de indicação de livros e risadas gostosas. Gostava de abraçar, de fofocar, de compartilhar, de conviver, de aglomerar, não era feito para esses tempos de pandemia. Essa pandemia que nos afastou dele, mas que ao mesmo tempo possibilitou que sua família ficasse ao lado dele, nessa reta final. Vai entender as contradições da vida...

Formou um grupo potente, que começou com três mestrandos e um penetra e hoje conta com quase dez doutores, tantos outros doutorandos e mestrandos. Meu mestre, meu pai intelectual, minha referência... havia coisas que só você podia me aconselhar, havia vitórias que eu precisava contar antes para você, que só você entendia a magnitude, quantos textos tínhamos ainda para escrever... parece que tudo que fiz foi para te orgulhar. Como você disse na minha defesa, um dia você iria encher a boca para falar que orientou "O Marcelo Mocarzel"! Também não deu tempo. Jorgito, nosso Grande Tubarão Branco, que valorizava cada ritual, cada pequeno passo de cada pessoa que Ihe cercava, fique sabendo que o câncer não te venceu. Porque um verdadeiro professor torna-se imortal em seus alunos. Esse talvez seja o nosso céu: habitar quem fica, de alguma forma.

Com você aprendi a fazer citações perfeitas, a beber café sem açúcar, a deixar os problemas virem até mim, a ajudar sem esperar nada em troca, a não falar "a nível de", a não só me indignar, mas a agir contra as injustiças, a buscar sempre o melhor em mim e no mundo. Você me ensinou que mestrado é formação intelectual e me obrigava a ler literatura e te acompanhar em exposições de arte enquanto eu só queria saber da 


\section{RevistAleph}

tese! Com você escrevi meu primeiro resumo, meu primeiro artigo, meu primeiro livro, fui ao meu primeiro congresso nacional e internacional, integrei a minha primeira banca. Você estava na minha banca de mestrado, na minha banca de professor substituto, na minha banca de doutorado e em todos os momentos importantes da minha vida; me viu casar, viu minhas duas filhas nascerem, viu eu me tornar professor do ensino superior, doutor, professor da pós, conselheiro... enfim, custo a crer que a vida vai ter a mesma graça sem você, sem você falando "E aí, filhote?". Mas como você sempre dizia, "a vida é dura, rapá"! E como Guimarães Rosa nos ensinou, o que ela quer da gente é coragem! Obrigado! Te amo para sempre!

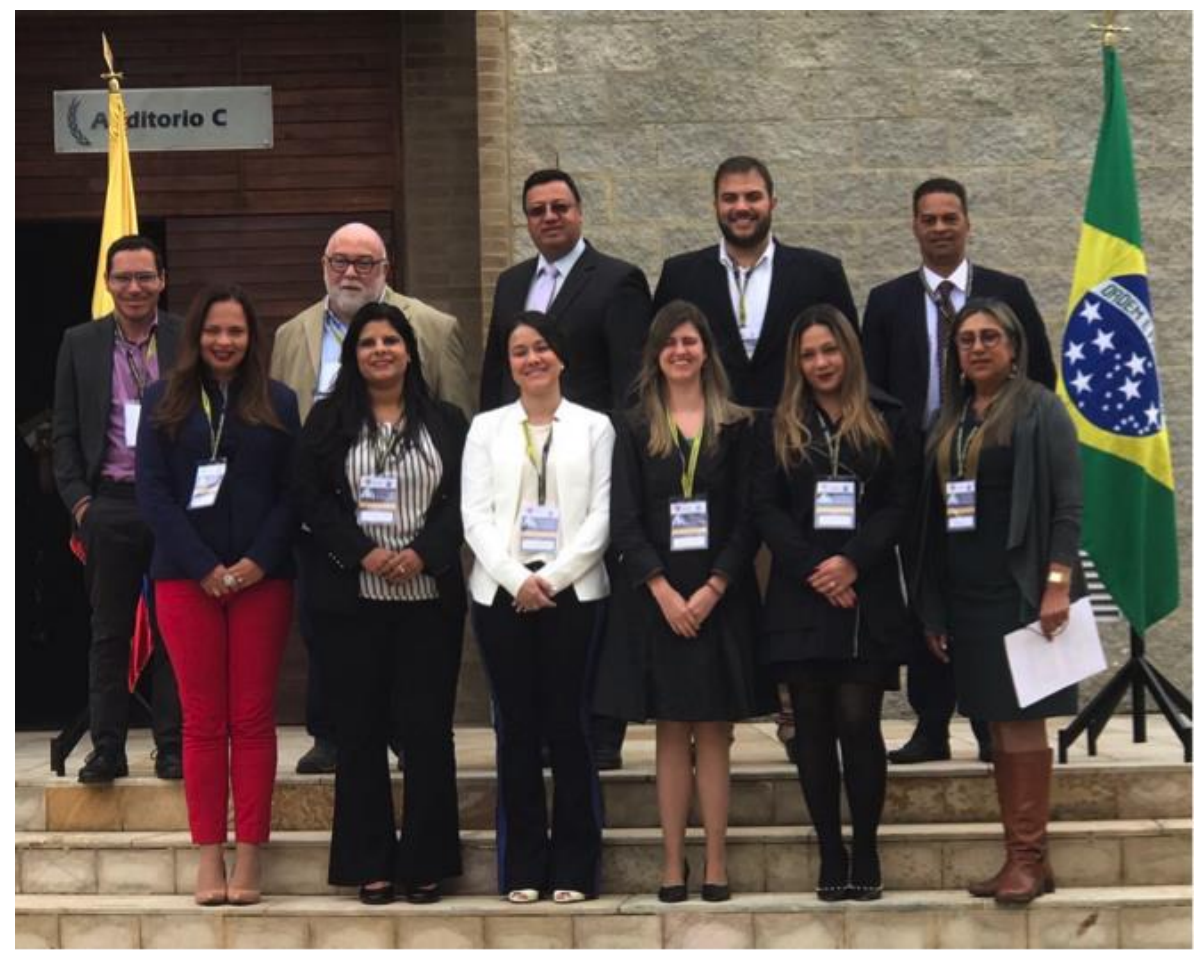

Fonte: Arquivo pessoal do autor. 